\title{
Effect of 5-aminolevulinic acid-based photodynamic therapy via reactive oxygen species in human cholangiocarcinoma cells
}

This article was published in the following Dove Press journal:

International Journal of Nanomedicine

29 June 2011

Number of times this article has been viewed

\section{Cy Hyun Kim ${ }^{1,2}$ \\ Chung-Wook Chung' \\ Kyung $\mathrm{Ha} \mathrm{Choi}^{1}$ \\ Jin-Ju Yoo' \\ Do Hyung Kim ${ }^{1,2}$ \\ Young-IL Jeong' \\ Dae Hwan Kang ${ }^{1,2}$,}

'National Research and Development Center for Hepatobiliary Cancer,

Research Institute for Convergence of Biomedical Science and Technology, Pusan National University Yangsan Hospital, Yangsan, Republic of Korea; ${ }^{2}$ School of Medicine, Pusan National University, Yangsan, Republic of Korea

The first two authors contributed equally to this work.
Correspondence: DH Kang 626-770 Beomeo-ri, Mulgeum-eup, Yangsan, Gyeongnam, Korea Tel +9 82553603870

Fax +982553603879

Emailsulsulpul@yahoo.co.kr
Abstract: Cancer cells have been reported to exhibit an enhanced capacity for protoporphyrin IX (PpIX) synthesis facilitated by the administration of 5-aminolevulinic acid (ALA). We investigated the effect of ALA-based photodynamic therapy (PDT) on human cholangiocarcinoma cells (HuCC-T1). Since protoporphyrin IX (PpIX), a metabolite of ALA, can produce reactive oxygen species (ROS) under irradiation and then induce phototoxicity, ALA-based PDT is a promising candidate for the treatment of cholangiocarcinoma. When various concentrations of ALA $(0.05-2 \mathrm{mM})$ were used to treat HuCC-T1 cells for 6 or 24 hours, the intracellular PpIX level increased according to the ALA concentration and treatment time. Furthermore, an increased amount of PpIX in HuCC-T1 cells induced increased production of ROS by irradiation, resulting in increased phototoxicity.

Keywords: ALA-based photodynamic therapy, HuCC-T1, protoporphyrin IX, ROS

\section{Introduction}

Cholangiocarcinoma (CC) is the second most common primary hepatobiliary malignancy in adults, and has high mortality. It often arises from background conditions that cause longstanding inflammation, injury, and reparative biliary epithelial cell proliferation, such as primary sclerosing cholangitis, clonorchiasis, hepatolithiasis, or complicated fibropolycystic diseases. ${ }^{1-5}$ The most common curative therapy for $\mathrm{CC}$ is surgical resection. However, the majority of patients are diagnosed in a latent CC state and, unfortunately, they are not considered for surgery. For this reason, alternative therapies such as stent replacement, chemotherapeutic, radiation therapy, and photodynamic therapy (PDT) are the treatments of choice for the management of CC. ${ }^{6-9}$ PDT typically involves systemic administration of a tumor-localizing photosensitizer followed by its activation by light of an appropriate wavelength to create a photochemical reaction, thus causing photodamage to the tumor. ${ }^{10,11}$

5-aminolevulinic acid (ALA) is a precursor of PpIX, which is well known as a strong photosensitizer, and administered ALA is interconverted to PpIX via the heme biosynthetic pathway. ${ }^{12-15}$ PpIX accumulation in tumor cells is generally higher than that in normal cells, as the activity of key enzymes in tumor cells is significantly changed. ${ }^{16-18}$ Excitation of PpIX under irradiation in tumor cells can produce a significant amount of reactive oxygen species (ROS), including singlet oxygen, superoxide, hydroxyl radical, and hydrogen peroxide. ROS causes DNA and cell membrane damage through lipid peroxidation and/or alterations in membrane fluidity. This reaction results in obvious damage to cellular organelles, such as mitochondria and microsomes, ${ }^{19-22}$ and causes the death of tumor cells. 
One of the main advantages of ALA-based PDT is that ALA-derived PpIX is cleared from the body within 24-48 hours after systemic ALA administration. This fact reduces or avoids the risk of prolonged phototoxicity to the human body. ${ }^{14-17}$ Recently, researchers reported the effects of ALA-based PDT in various tumor cells such as oral squamous cell carcinoma, melanoma, glioma, lymphoma, esophageal carcinoma, and basal cell carcinoma. ${ }^{10,23-27}$ ALA and its derivatives are therefore considered a potential treatment option for hepatobiliary cholangiocarcinoma therapy.

In this study, the effect of ALA treatment on PpIX synthesis, ROS production, and cell death in cholangiocarcinoma cells was investigated. To the authors' knowledge, there has been no in vitro study of the potential of ALA-based PDT in HuCC-T1 cells. Since ALA is regarded as safe for PDT compared with other photosensitizers, the application of ALAbased PDT will provide a new treatment option for CC.

\section{Methods \\ Materials}

5-aminolevulinic acid (ALA), 2', 7'-dichlorofluorescein diacetate (DCFH-DA), 3-[4,5-dimethylthiazol-2-yl]-2,5diphenyltetrazolium bromid (MTT), and propidium iodide (PI) were purchased from Sigma-Aldrich Co (St Louis, MI). FITC-Annexin V was obtained from Santa Cruz Biotechnology, Inc (Santa Cruz, CA). Cell culture materials were purchased from Invitrogen (New York, NY).

\section{Cell culture}

The human intrahepatic cholangiocarcinoma cell line (HuCC-T1) was used in this study. The cells were routinely propagated in Gibco ${ }^{\circledR}$ RPMI medium supplemented with $10 \%$ fetal bovine serum and $1 \%$ antibiotics at $37^{\circ} \mathrm{C}$ in a humidified atmosphere of $5 \% \mathrm{CO}_{2}: 95 \%$ air according to the procedure described by Miyagiwa et al. ${ }^{1}$ Every 3 days, trypsin-EDTA ( $0.05 \%$ trypsin and $0.02 \%$ EDTA) was used for subculture.

\section{Dark toxicity}

HuCC-T1 cells $\left(1 \times 10^{4}\right)$ were seeded into a 96-well plate and treated with various concentrations $(0.05-2 \mathrm{mM})$ of ALA in serum-free medium for 6 or 24 hours. After that, the medium was changed to growth medium containing $10 \%$ fetal bovine serum and incubated for 24 hours. Cell viability was measured by MTT assay. ${ }^{28}$

\section{PplX accumulation assay}

HuCC-T1 cells were treated with various concentrations of ALA for 6 or 24 hours. After that, cells were lysed using cell lysis buffer (GenDEPOT, Barker, TX). PpIX accumulation in the cells was measured by fluorescence intensity using a microplate reader (Infinite M200 Pro, Tecan Group Ltd, Mannerdorf, Switzerland) at an excitation wavelength of $485 \mathrm{~nm}$ and emission wavelength of $635 \mathrm{~nm}$.

\section{Light sources for photodynamic therapy}

Cultured cell plates were exposed to LED lamps at $635 \mathrm{~nm}$ for irradiation (SH System Co, Gwangju, Korea). Light intensity was $0.25 \mathrm{~J} / \mathrm{cm}^{2}$, as measured by a photo radiometer (Delta Ohm, Padua, Italy).

\section{Cell viability assay}

HuCC-T1 cells were treated with various concentrations of ALA in serum-free medium for 6 or 24 hours. After incubation with ALA, the cells were irradiated at $635 \mathrm{~nm}$ with $0.25 \mathrm{~J} / \mathrm{cm}^{2}$. The medium was changed to growth medium containing $10 \%$ fetal bovine serum and incubated for 24 hours. Cell viability was measured by MTT assay. ${ }^{28}$

\section{ROS measurement}

After irradiation, ROS generation by PpIX-accumulated HuCC-T1 cells was measured by the DCFH-DA method. ${ }^{29}$ In this method, fluorogenic substrate DCFH-DA, a cellpermeable dye, is oxidized to highly fluorescent DCF by ROS, and can be used to monitor intracellular generation of ROS. The cells were treated with various concentrations $(0.05-2 \mathrm{mM})$ of ALA for 24 hours in phenol red free RPMI media. DCFH-DA was added to the media at a final concentration of $20 \mu \mathrm{M}$ and incubated at $37^{\circ} \mathrm{C}$ for 30 minutes. After irradiation at $635 \mathrm{~nm}$, ROS generation was measured by fluorescence intensity at an excitation wavelength of $485 \mathrm{~nm}$ and emission wavelength of $535 \mathrm{~nm}$ using a microplate reader.

\section{Flow cytometry analysis}

Two reagents, PI and FITC-annexin V, were used to identify apoptosis and necrosis of HuCC-T1 cells, respectively. Cells were treated with various concentrations of ALA for 24 hours. After that, cells were irradiated at $635 \mathrm{~nm}$ with $0.25 \mathrm{~J} / \mathrm{cm}^{2}$, then collected cells were washed with phosphate-buffered saline (PBS). The pellets were resuspended with binding buffer (10 mM 4-(2-hydroxyethyl)-1-piperazineethanesulfonic acid [HEPES] $\mathrm{pH} 7.4,150 \mathrm{mM} \mathrm{NaCl}, 5 \mathrm{mM} \mathrm{KCl}$, $1 \mathrm{mM} \mathrm{MgCl} 2,1.8 \mathrm{mM} \mathrm{CaCl}_{2}$ ) containing FITC-annexin $\mathrm{V}$ $(1 \mathrm{ug} / \mathrm{mL})$ and further incubated for 30 minutes. Ten minutes prior to termination of incubation, PI $(10 \mathrm{ug} / \mathrm{mL})$ was added to stain necrotic cells under dark conditions. Following that, 
the cells were immediately analyzed using a FACScan flow cytometer (Becton Dicknson Biosciences, San Jose, CA).

\section{Fluorescence microscopy}

PpIX products were observed by fluorescence microscopy. The microscope (Eclipse 80i; Nikon, Tokyo, Japan) was equipped with a $460-480 \mathrm{~mm}$ excitation filter and a $610 \mathrm{~nm}$ filter for detection of PpIX fluorescence. $1 \times 10^{6}$ HuCC-T1 cells were seeded on a cover glass in a 6-well plate. The cells were then treated with $0.25 \mathrm{mM}$ ALA for 24 hours in serum-free media, after which the medium was discarded and washed with PBS. The cells were fixed by $4 \%$ paraformaldehyde in PBS, mounted on a glass slide, and observed using a fluorescence microscope.

\section{Phase contrast microscopy}

Cell death by ALA-PDT was observed by phase contrast microscopy (MCXI 600; Micros, Vienna, Austria). $1 \times 10^{6}$ HuCC-T1 cells were seeded in a 6-well plate. The cells were then treated with $0.25 \mathrm{mM}$ ALA for 24 hours in serum-free media.

\section{Statistical analysis}

All the experiments in this study were performed in triplicate, ie, average plus standard deviation value was obtained from three independent experiments. All data are shown as the mean \pm SEM of the independent experiments. Statistical analysis was performed using Student's $t$-test (SPSS Data Collection [IBM Corp, Somers, NY] software). Statistical significance was taken as $P<0.001$.

\section{Results}

\section{Dark toxicity of HuCC-TI cells by ALA}

To identify dark toxicity, various concentrations of ALA were treated to HuCC-T1 cells for 6 or 24 hours without radiation (Figure 1). When the HuCC-T1 cells were incubated with less than $0.5 \mathrm{mM}$ ALA for 6 hours or $0.25 \mathrm{mM}$ ALA for 24 hours, their survivability did not significantly change, ie, more than $90 \%$ of cells survived. Dark toxicity of cells appeared at greater than $0.5 \mathrm{mM}$ at 6 hours treatment and $0.25 \mathrm{mM}$ at 24 hours treatment.

\section{PpIX production by ALA}

PpIX accumulation in HuCC-T1 cells incubated with ALA was assessed for 6 or 24 hours. Production of PpIX in HuCC-T1 cells was extremely high after 24 hours treatment with $1 \mathrm{mM}$ ALA (Figure 2A). PpIX accumulation in HuCC-T1 cells induced by $0.25 \mathrm{mM}$ ALA treatment for

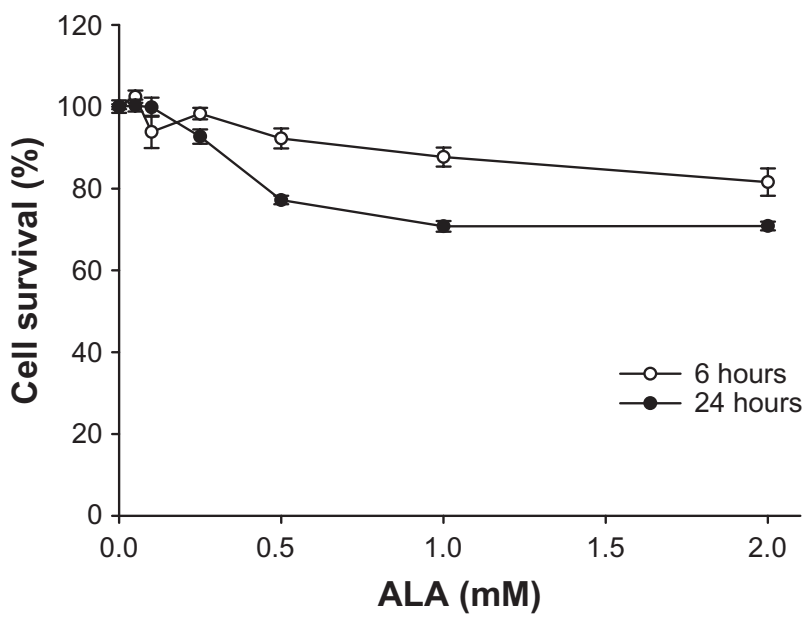

Figure I Cell dark toxicity by ALA treatment in HuCC-TI cells. HuCC-TI cells were treated with ALA $(0,0.05,0.1,0.25,0.5,1,2 \mathrm{mM})$ in serum-free culture medium. These cells were incubated for 24 hours in normal media containing $10 \%$ FBS. Cell survival was determined by measuring MTT. HuCC-TI cells treated with ALA concentrations of $0.5 \mathrm{mM}$ for 6 hours and 0.25 -mM for 24 hours did not significantly influence cell survival ( $>90 \%)$.

Abbreviations: ALA, 5-aminolevulinic acid; HuCC-TI, human cholangiocarcinoma cells; MTT, 3-[4,5-dimethylthiazol-2-yl]-2,5-diphenyltetrazolium bromide.

24 hours was observed by phase contrast and fluorescence confocal microscopy. As shown in Figure 2B, red fluorescence was observed in the sample treated with $0.25 \mathrm{mM}$ ALA, but no fluorescence signal was observed in the control group. These results indicate that administered ALA could be successfully interconverted to PpIX in HuCC-T1 cells.

\section{Cell death induced by ALA-PDT}

First, cell death by ALA-PDT was measured by MTT assay. HuCC-T1 cells were treated with ALA at various concentrations for 6 or 24 hours. The survivability of HuCC-T1 cells after irradiation was significantly decreased by $1 \mathrm{mM}$ ALA treatment for 6 hours and $0.5 \mathrm{mM}$ ALA for 24 hours, as shown in Figure 3A. When the exposure time of tumor cells to ALA was increased, photocytotoxicity increased in a similar range. Second, cell death induced by ALA-PDT in HuCC-T1 cells was identified by photomicrographs, as shown in Figure 3B. Whereas cell density was clearly decreased by treatment with $0.25 \mathrm{mM}$ ALA, control treatment resulted in many cells. These results indicate that ALA-PDT induces death of HuCC-T1 cells.

\section{Apoptosis and necrosis induced by ALA-PDT}

After ALA-based PDT, tumor cells were stained with FITCannexin $\mathrm{V}$ for apoptotic cells (Figure 4A) and PI for necrotic cells (Figure 4B). As shown in Figure 4, the number of apoptotic cells gradually increased according to the increase in ALA concentration. Furthermore, the number of necrotic cells 


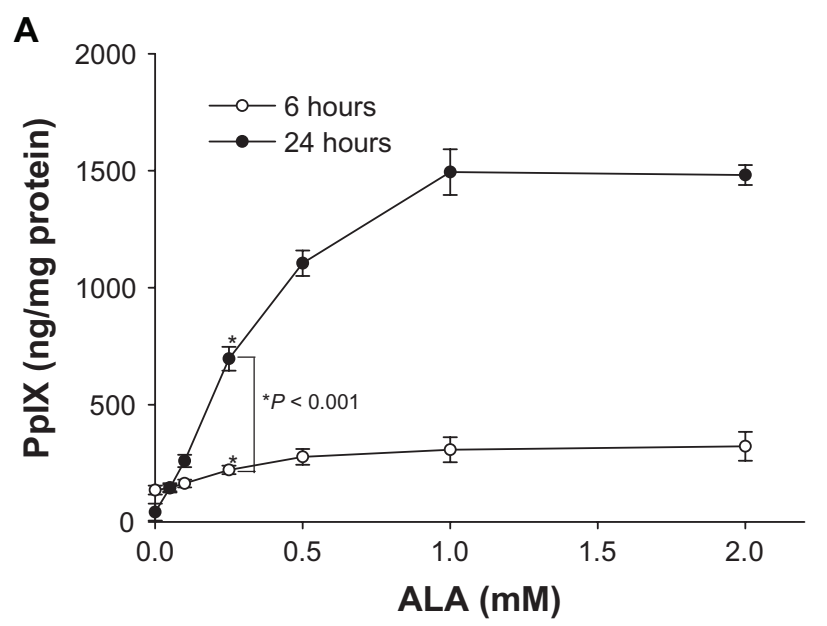

B

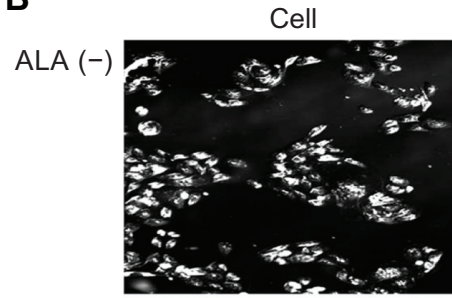

ALA (+)
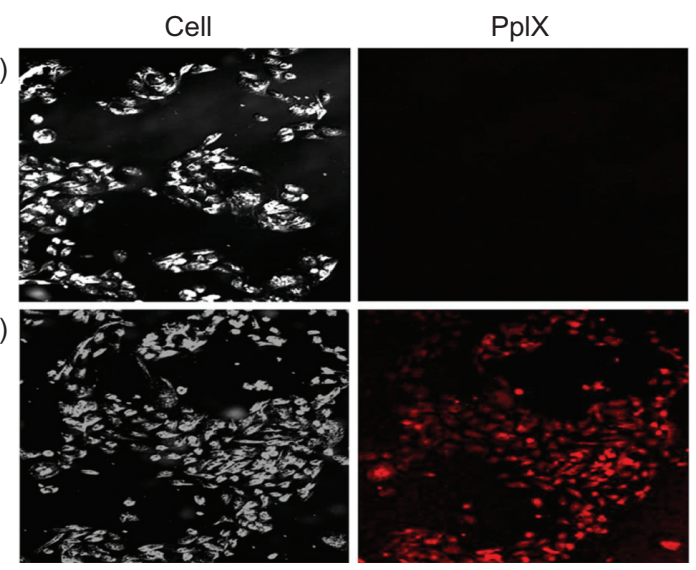

Figure 2 PpIX accumulation graph induced by ALA treatment for 6 or 24 hours in HuCC-TI cells (A) and photomicrographs of PpIX accumulation induced by ALA $(0.25 \mathrm{mM})$ or non-treatment in HuCC-TI cells (B).

Abbreviations: ALA, 5-aminolevulinic acid; HuCC-TI, human cholangiocarcinoma cells; PpIX, protoporphyrin IX.

also dramatically increased according to ALA concentration (Figures 4A, 4C). These results indicate that ALA-based PDT induces death of HuCC-T1 cells through apoptosis and necrosis.

\section{ROS generation by ALA-PDT}

As shown in Figure 4D, the ROS level gradually increased as the ALA concentration was increased to $0.5 \mathrm{mM}$ after ALAbased PDT. These results could be explained by the fact that synthesis of PpIX after 24 hours incubation was saturated above $0.5 \mathrm{mM}$ ALA. Therefore, ROS were produced by ALA-PDT, and the ROS level increased according to the increase in ALA concentration. In addition, ROS generation by ALA-based PDT was associated with cell death (Figures 3A, 4D).

\section{Discussion}

Administration of ALA both in vitro and in vivo is known to enhance PpIX synthesis in cancer cells. Frank et al reported
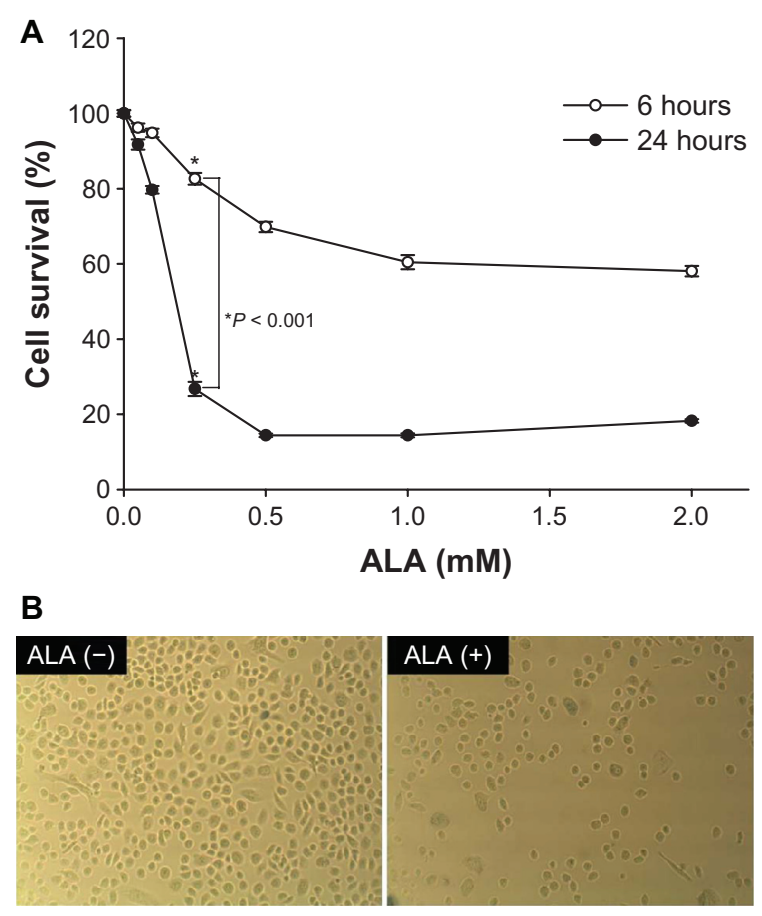

Figure 3 Effect of ALA-PDT in HuCC-TI cells (A) and photomicrographs of HuCC-TI cell death by ALA-PDT (B).

Abbreviations: ALA-PDT, 5-aminolevulinic acid-photodynamic therapy; HuCC-TI, human cholangiocarcinoma cells.

that PpIX accumulation in cancer cells is significantly higher than that in normal human fibroblasts. ${ }^{18}$ After irradiation, the PpIX-accumulated tumor cells produced ROS, which destroy tumor cells by apoptosis or necrosis. ${ }^{20-22,30}$ The advantage of ALA-based PDT is its ability to target tumor cells. ROS generation in cancer cells can be specifically amplified by local irradiation even though ALA is distributed throughout the whole body.

Recently, researchers have reported that ALA-based PDT can effectively inhibit tumor cell growth and enhance patient survivability. Inoue et al reported massive apoptotic cell death in human glioma cells after ALA-based PDT. ${ }^{27}$ Furthermore, the efficacy of ALA-based PDT was reported in melanoma cells ${ }^{10}$ and oral squamous cell carcinoma. ${ }^{11}$

The main obstacle to the treatment of CC is the fact that CC develops deeper than the skin, making application of chemotherapy and radiotherapy difficult. ALA-based PDT has advantages in that ALA can be delivered locally by endoscopic operation, which allows for specific accumulation of PpIX in the tumor cells. ${ }^{31}$ Furthermore, local application of ALA-based PDT by endoscopic operation enables avoidance of the undesirable side effects of photosensitizers compared with systemic application.

Before ALA-based PDT using HuCC-T1 cells was tested, it was confirmed whether the cell death effect was 
A

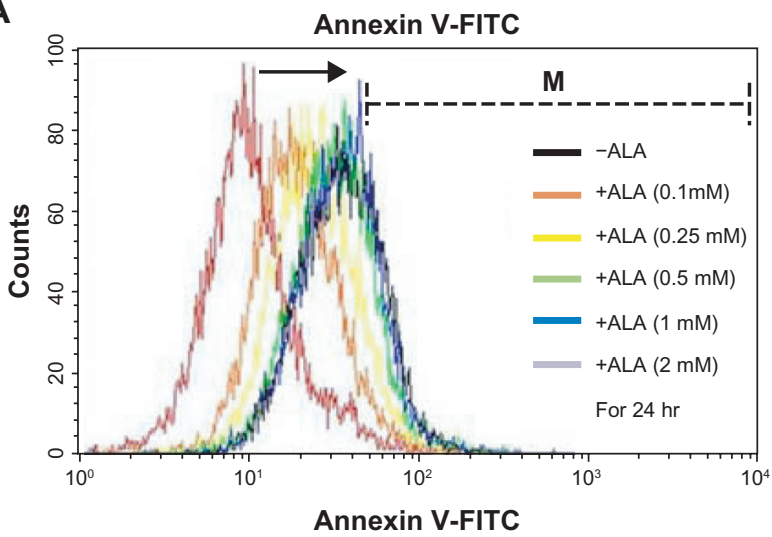

B

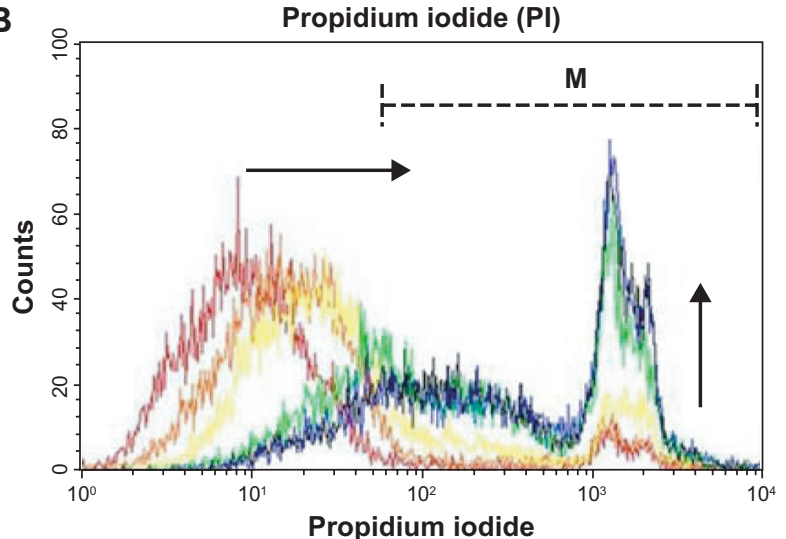

C

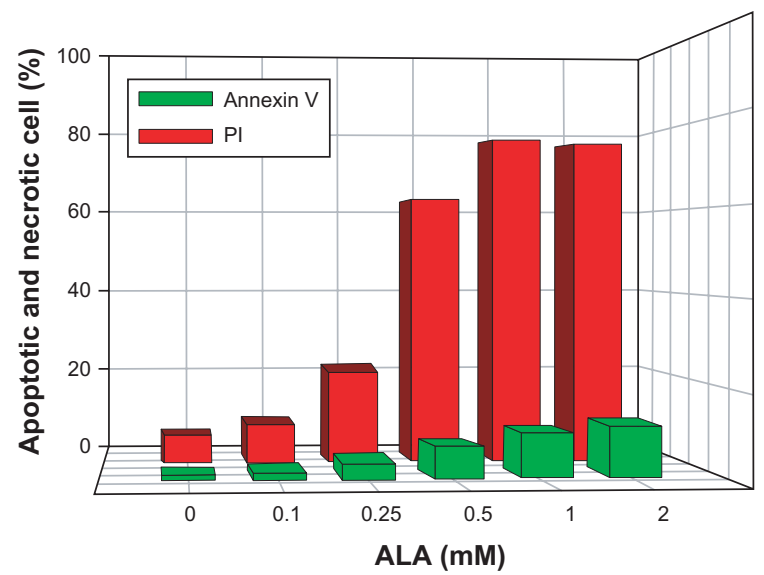

D

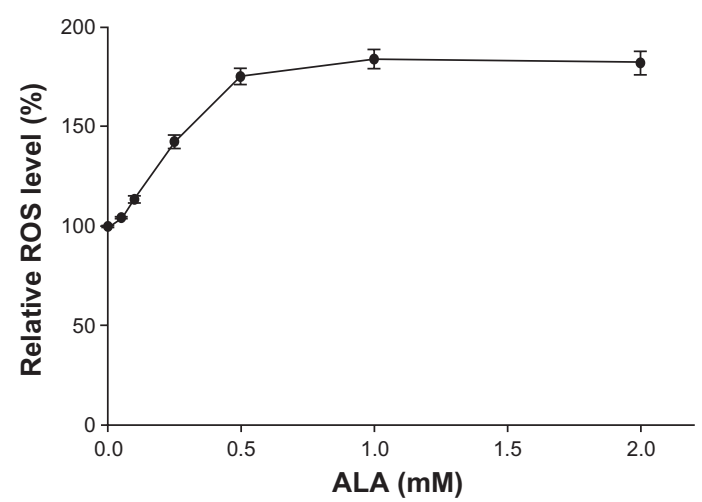

Figure 4 Apoptosis, necrosis, and ROS generation induced by ALA-PDT in HuCC-TI cells. After ALA or nontreatment for 24 hours, HuCC-TI cells were illuminated at 635 nm. Cells were stained with FITC-annexin V (A) and propidium iodide (B) and analyzed using a flow cytometer. Arrows indicate direction of graph movement. (C) This graph displays percentage (\%) of cells in M (dotted line) area of total cells. After irradiation, ROS production in the cells was immediately measured by fluorescence intensity (D).

Abbreviations: ALA-PDT, 5-aminolevulinic acid-photodynamic therapy; HuCC-TI, human cholangiocarcinoma cells; ROS, reactive oxygen species.

caused only by photoinduced cytotoxicity. The cytotoxicity of ALA in the absence of a light source (without irradiation and dark conditions) was investigated. When the ALA concentration was less than $0.5 \mathrm{mM}$ at 6 hours incubation, the survivability of HuCC-T1 cells did not significantly change, ie, more than $90 \%$ of tumor cells survived as shown in Figure 1. Furthermore, a similar result was observed at a greater incubation time and lower dose, ie, 24 hours incubation at $0.25 \mathrm{mM}$ ALA also did not significantly affect cell survivability. The viability of tumor cells decreased at more than $0.5 \mathrm{mM}$ ALA at 6 hours incubation. Moreover, when the incubation time was increased to 24 hours, the effective dose of ALA decreased; ie, viability of tumor cells decreased at $0.25 \mathrm{mM}$ ALA. In the absence of irradiation, ALA itself did not affect cell survivability at any concentration. PpIX accumulation induced by ALA in HuCC-T1 cells reached its maximum at $1 \mathrm{mM}$ ALA (Figure 2A). These results indicate that the ALA-based-PDT effect against human cholangiocarcinoma cells is dependent on the ALA concentration and incubation time. In addition, apoptosis and necrosis was identified in HuCC-T1 cells by ALA-PDT using FITC-annexin V and PI. The numbers of apoptotic and necrotic cells gradually increased on treatment with $1 \mathrm{mM}$ ALA for 24 hours, indicating that the viability of HuCC-T1 cells decreased (Figure 4). This result corresponds with the fact that PpIX accumulation was maximal at $1 \mathrm{mM}$ ALA. Although the necrosis of tumor cells was dominant over apoptosis as shown in Figure 4, secondary necrotic cells/late apoptotic cells might have been present in the necrotic population, since these secondary necrotic/ late apoptotic cells represent cells that were initially apoptotic before losing membrane integrity due to a lack of timely phagocytosis. Even though apoptosis/necrosis dual staining did not strictly differentiate secondary necrotic/ late apoptotic cells from necrosis of tumor cells, the results show a positive corelationship between apoptosis/necrosis of tumor cells and cell death. Furthermore, ROS generation in HuCC-T1 cells gradually increased upon treatment with $1 \mathrm{mM}$ ALA for 24 hours (Figure 5). This result supports ALA-dependent death of HuCC-T1 cells after 24 hours 
incubation as shown in Figure 3A. After 6 hours incubation with various concentrations of ALA, the survivability of cells gradually decreased, and a significant decrease in cell survival was observed after 24 hours incubation with $0.5 \mathrm{mM}$ ALA. These results indicate that ROS generation by PDT in HuCC-T1 cells is simultaneously dependent on incubation time and ALA concentration. Cao et al reported that hematoporphyrin, a photosensitizer similar to ALA, exhibits a PDT-mediated cytotoxic effect against human cholangiocarcinoma cells both in vitro and in vivo. ${ }^{32}$ The results of the authors' study show that ALA-based PDT is no less effective for treatment of human cholangiocarcinoma than hematoporphyrin.

In conclusion, a positive relationship between ALA concentration, PpIX accumulation, ROS production, and cell death by ALA-based PDT was observed. The results indicate that an appropriate concentration of ALA and treatment time is required to maximize the effects of ALA-based PDT and to minimize side effects. It is concluded that ALA-based PDT is a promising treatment option for $\mathrm{CC}$.

\section{Acknowledgment}

This study was supported by a grant from the Korea Healthcare Technology R\&D Project, Ministry for Health Welfare and Family Affairs, Republic of Korea (A091047).

\section{Disclosure}

The authors declare no conflicts of interest in relation to this paper.

\section{References}

1. Miyagiwa M, Ichida T, Tokiwa T, Sato J, Sasaki H. A new human cholangiocellular carcinoma cell line (HuCC-T1) producing carbohydrate antigen 19/9 in serum-free medium. In Vitro Cell Dev Biol. 1989;25(6): 503-510.

2. Wu GS, Zou SQ, Liu ZR, Tang ZH, Wang JH. Celecoxib inhibits proliferation and induces apoptosis via prostaglandin E2 pathway in human cholangiocarcinoma cell lines. World J Gastroenterol. 2003; 9(6):1302-1306.

3. Wu T, Leng J, Han C, Demetris AJ. The cyclooxygenase-2 inhibitor celecoxib blocks phosphorylation of Akt and induces apoptosis in human cholangiocarcinoma cells. Mol Cancer Ther. 2004;3(3):299-307.

4. Afford SC, Ahmed-Choudhury J, Randhawa S, et al. CD40 activationinduced, Fas-dependent apoptosis and NF-kappaB/AP-1 signaling in human intrahepatic biliary epithelial cells. FASEB J. 2001;15(13):2345-2354.

5. Wise C, Pilanthananond M, Perry BF, Alpini G, McNeal M, Glaser SS. Mechanisms of biliary carcinogenesis and growth. World J Gastroenterol. 2008;14(19):2986-2989.

6. Karamitopoulou E, Tornillo L, Zlobec I, et al. Clinical significance of cell cycle- and apoptosis-related markers in biliary tract cancer: a tissue microarray-based approach revealing a distinctive immunophenotype for intrahepatic and extrahepatic cholangiocarcinomas. Am J Clin Pathol. 2008;130(5):780-786.

7. Joplin R. Isolation and culture of biliary epithelial cells. Gut. 1994;35(7): 875-878.
8. Kang R, Saito H, Ihara $\mathrm{Y}$, et al. Transcriptional regulation of the $\mathrm{N}$-acetylglucosaminyltransferase $\mathrm{V}$ gene in human bile duct carcinoma cells (HuCC-T1) is mediated by Ets-1. J Biol Chem. 1996;271(43): 26706-26712.

9. Muff MA, Masyuk TV, Stroope AJ, et al. Development and characterization of a cholangiocyte cell line from the PCK rat, an animal model of autosomal recessive polycystic kidney disease. Lab Invest. 2006;86(9):940-950.

10. Grimm S, Mvondo D, Grune T, Breusing N. The outcome of 5-ALAmediated photodynamic treatment in melanoma cells is influenced by vitamin C and heme oxygenase-1. Biofactors. 2011;37(1):17-24.

11. Moon YH, Park JH, Kim SA, Lee JB, Ahn SG, Yoon JH. Anticancer effect of photodynamic therapy with hexenyl ester of 5-aminolevulinic acid in oral squamous cell carcinoma. Head Neck. 2010;32(9): $1136-1142$.

12. Malik Z, Kostenich G, Roitman L, Ehrenberg B, Orenstein A. Topical application of 5-aminolevulinic acid, DMSO and EDTA: protoporphyrin IX accumulation in skin and tumours of mice. J Photochem Photobiol B. 1995;28(3):213-218.

13. Peng Q, Berg K, Moan J, Kongshaug M, Nesland JM. 5-Aminolevulinic acid-based photodynamic therapy: principles and experimental research. Photochem Photobiol. 1997;65(2):235-251.

14. Peng Q, Warloe T, Berg K, et al. 5-Aminolevulinic acid-based photodynamic therapy. Clinical research and future challenges. Cancer. 1997;79(12):2282-2308.

15. De Rosa FS, Marchetti JM, Thomazini JA, Tedesco AC, Bentley MV. A vehicle for photodynamic therapy of skin cancer: influence of dimethylsulphoxide on 5-aminolevulinic acid in vitro cutaneous permeation and in vivo protoporphyrin IX accumulation determined by confocal microscopy. J Control Release. 2000;65(3):359-366.

16. Peng Q, Warloe T, Moan J, et al. Antitumor effect of 5-aminolevulinic acid-mediated photodynamic therapy can be enhanced by the use of a low dose of photofrin in human tumor xenografts. Cancer Res. 2001;61(15):5824-5832.

17. Pierre MB, Tedesco AC, Marchetti JM, Bentley MV. Stratum corneum lipids liposomes for the topical delivery of 5-aminolevulinic acid in photodynamic therapy of skin cancer: preparation and in vitro permeation study. BMC Dermatol. 2001;1:5.

18. Frank J, Lornejad-Schäfer MR, Schöffl H, Flaccus A, Lambert C, Biesalski HK. Inhibition of heme oxygenase-1 increases responsiveness of melanoma cells to ALA-based photodynamic therapy. Int J Oncol. 2007;31(6):1539-1545.

19. Sharma S, Jajoo A, Dube A. 5-aminolevulinic acid-induced protoporphyrin-IX accumulation and associated phototoxicity in macrophages and oral cancer cell lines. $J$ Photochem Photobiol B. 2007;88(2-3):156-162.

20. Chen R, Huang Z, Chen G, et al. Kinetics and subcellular localization of 5-ALA-induced PpIX in DHL cells via two-photon excitation fluorescence microscopy. Int J Oncol. 2008;32(4):861-867.

21. Donnelly RF, McCarron PA, Woolfson AD. Derivatives of 5-aminolevulinic acid for photodynamic therapy. Perspect Med Chem. 2007;11(1):49-63.

22. Fotinos N, Mikulic J, Convert M, et al. 5-ALA derivative-mediated photoinactivation of Propionibacterium acnes. J Dermatol Sci. 2009; 56(3):214-216.

23. Ickowicz Schwartz D, Gozlan Y, Greenbaum L, Babushkina T, Katcoff DJ, Malik Z. Differentiation-dependent photodynamic therapy regulated by porphobilinogen deaminase in B16 melanoma. $\mathrm{Br} J$ Cancer. 2004;90(9):1833-1841.

24. Maier A, Tomaselli F, Matzi V, Rehak P, Pinter H, Smolle-Jüttner FM. Photosensitization with hematoporphyrin derivative compared to 5 -aminolaevulinic acid for photodynamic therapy of esophageal carcinoma. Ann Thorac Surg. 2001;72(4):1136-1140.

25. Redondo P, Marquina M, Pretel M, Aguado L, Iglesias ME. MethylALA-induced fluorescence in photodynamic diagnosis of basal cell carcinoma prior to Mohs micrographic surgery. Arch Dermatol. 2008;144(1):115-117. 
26. Amo T, Kawanishi N, Uchida M, et al. Mechanism of cell death by 5-aminolevulinic acid-based photodynamic action and its enhancement by ferrochelatase inhibitors in human histiocytic lymphoma cell line U937. Cell Biochem Funct. 2009;27(8):503-515.

27. Inoue $\mathrm{H}$, Kajimoto $\mathrm{Y}$, Shibata MA, et al. Massive apoptotic cell death of human glioma cells via a mitochondrial pathway following 5-aminolevulinic acid-mediated photodynamic therapy. J Neurooncol. 2007;83(3):223-231.

28. Mosmann T. Rapid colorimetric assay for cellular growth and survival: application to proliferation and cytotoxicity assays. J Immunol Methods. 1983;65(1-2):55-63.

29. Heo HY, Park JM, Kim CH, Han BS, Kim KS, Seol W. LRRK2 enhances oxidative stress-induced neurotoxicity via its kinase activity. Exp Cell Res. 2010;316(4):649-656.
30. Ito S, Miyoshi N, Degraff WG, Nagashima K, Kirschenbaum LJ, Riesz P. Enhancement of 5-aminolevulinic acid-induced oxidative stress on two cancer cell lines by gold nanoparticles. Free Radic Res. 2009;43(12):1214-1224.

31. Brancaleon L, Moseley H. Laser and non-laser light sources for photodynamic therapy. Lasers Med Sci. 2002;17(3):173-186.

32. Cao LQ, Xue P, Lu HW, Zheng Q, Wen ZL, Shao ZJ. Hematoporphyrin derivative-mediated photodynamic therapy inhibits tumor growth in human cholangiocarcinoma in vitro and in vivo. Hepatol Res. 2009;39(12):1190-1197.
International Journal of Nanomedicine

\section{Publish your work in this journal}

The International Journal of Nanomedicine is an international, peerreviewed journal focusing on the application of nanotechnology in diagnostics, therapeutics, and drug delivery systems throughout the biomedical field. This journal is indexed on PubMed Central,

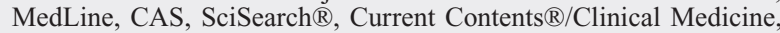

\section{Dovepress}

Journal Citation Reports/Science Edition, EMBase, Scopus and the Elsevier Bibliographic databases. The manuscript management system is completely online and includes a very quick and fair peer-review system, which is all easy to use. Visit http://www.dovepress.com/ testimonials.php to read real quotes from published authors.

Submit your manuscript here: http://www.dovepress.com/international-journal-of-nanomedicine-journal 